\title{
INTEGRAL INEQUALITIES FOR SECOND-ORDER LINEAR OSCILLATION
}

\author{
MAN KAM KWONG
}

Abstract. We present several results related to the classical Lyapunov inequality for the oscillation of second-order linear equations. The first is an improved Lyapunov inequality given in terms of the downswing of the functions $\int_{a}^{t}(t-a) q(t) d t$ and $\int_{t}^{b}(b-t) q(t) d t$, extending earlier results of Kwong and Harris and Kong. Nonoscillation criteria are derived as corollaries. A Lyapunovtype inequality for two consecutive zeros of the derivative of a solution is then established and a nonoscillation criterion given as a corollary. An oscillation criterion for positive $q(t)$ is also proved. It extends the known condition $\int t^{\gamma} q(t) d t=\infty, \gamma \in[0,1)$.

Mathematics subject classification (1991): 34C10, 26D10.

Key words and phrases: Lyapunov inequality, oscillation, second-order linear differential equation.

\section{REFERENCES}

[1] BRown, R. C. AND Hinton, Don B., Opial's inequality and oscillation of second-order equations, Proc. Amer. Math. Soc. 125 (1997), 1123-1129

[2] Clark, Steve and Hinton, Don B., A Liapunov inequality for linear Hamiltonian systems, Math. Inequal. Appl. 1 (1998), 201-209.

[3] HARRIS, B. J. AND KONG, Q., On the oscillation of differential equations with an oscillatory coefficient, Trans. Amer. Math. Soc., 347 (1995), 1831-1839.

[4] KwONG, MAn KAM, On Lyapunov's inequality for disfocaility, J. Math. Anal. Appl. 83 (1981), 486-494.

[5] WILLET, D., On the oscillatory behavior of the solutions of second-order linear differential equations, Ann. Polon. Math., 21 (1969), 175-194.

[6] Wong, James S. W., On second-order nonlinear oscillation, Funkcialaj. Ekvacioj, 11 (1968), 207-234.

[7] WONG, JAMES S. W., Oscillation and nonoscillation of solutions of second-order linear differential equations with integrable coefficients, Trans. Amer. Math. Soc., 144 (1969), 197-215.

[8] Swanson, C. A., Comparison and Oscillation Theory of Differential Equations, Academic Press, New York, London (1968). 